"lager geschat zijn de daarop door onze instelling gegeven lee,ningen. Wijlen Uw collega bleek met ons van meening te zijn, "dat het belang onzer vennootschap niet gediend wordt door op "dit punt bijzondere aandacht te vestigen; ook hij was van oor", deel, dat in dit geval slechts sprake is van een tijdelijke af,wijking en dat een gezonde verhouding tusschen onderpands,warde en leening weder zal bestaan, zoodra de huizenmarkt ",weder een normal beeld zal vertoonen.

.Commissarissen vertrouwen, dat $\mathrm{U}$ zich met deze logische ,opvatting zult kumnen vereenigen.

,Voor de gocde orde deel ik U verder nog mede, dat het ugeen gewoonte is de hymothecaire inschrijuingen door den ac„countant te doen rechercheeren. Dt dossiers der verleende hy"potheken bevatten titeraard alle gegevens, welke de accoun"tant voor zijn controle noodig heeft en het heeft geen zin ,kosten te maken voor een onderzoek, dat overbodig mag hee,ten.

,Wij verzoeken $U$ ons omgaand te doen weten, of (iij het „werk van wijlen Uw collega wilt afmaken en U daarna met de "regelmatige controle der administratie wilt belasten."

(jevraagd wordt:

a. in een gemotiveerd antwoord uiteen te zettell, onder welke voorwaarden ( $\mathrm{ij}$ bereid zoud zijn deze opdracht te aanvaarden en

b. afzonderlijk te vermelden de technische bijzonderlieden omtrent het door den accountant te verrichten werk, voor zoover $U$ het ongewenscht acht deze in den brief aan de Commissaris op te nemen.

\section{REPERTORIUM VAN TIJDSCHRIFT-LITERATUUR OP HET GEBIED VAN ACCOUNTANCY EN BEDRIJFSHUISHOUDKUNDE}

\section{Red.: Mej. Dr. R. PHILIPS en Drs. G. L. GROENEVELD voor bedrijfseconomie en J. P. DE HAAN en \\ J. C. SPANGENBERG voor accountancy}

\section{A. ACCOUNTANCY}

\section{I.EER VAN DE INRICHTING}

Ad:ninistratieve inrichting

Hu uck, H. F. - Cietft algemeene regels, waaraan bij de inrichting van administraties dient te worden gedacht.

A III 1

Administraticve Arbeid September 1936

¿̇eil en ander over de gemeentelijke onderneming

$\mathrm{H}$ I $\mathrm{red}, \mathrm{H}$ - Besproken wordt de centrale, administratieve organisatic voor een aantal onderdeelen van gemeentelijke bemoeienis, zooals publieke werken; srondbedrijf; reiniging; enz.

A III 3

Maandhlad y.h. Boekhouden September 1936

Fondsenbalans

Z. W. F., - Besproken wordt de fondsenbalans ell het verband met de geidadministratie.

A 1113

Maandblad v. h. Boekhouden December 1935

Het gemeentelijk grondbedrijf

Keyser, J. N. - Beschreven wordt het doel en de boekhouding van het gemeentelijk grondbedrijf.

A III 3

Maandblad v. h. Boekhouden December 1935

De boekhouding van een electro-technische installatie-bureau

[) ij $\mathrm{k}$, I. S. C. v a 11 - De administratie van bovengenoend bedrijf wordt beschrevell.

A Iil 3

Maandblad v. h. Boekhouden December 1935

Het streven naar uniformiteit in de boekhouding

$\mathrm{N}$ ijst, J. J. M. H. - Schrijver geeft een overzicht van hetgeen verschillende personen in binnen- en buitenland over dit onderwerp hebben gezegd.

A 1113

Maandblad v. h. Boekhouden Januari 1936

Het slipsysteem in de administratic

Turk, Drs. W. P. d c n - Besproken wordt het slipsysteen in de administratie in het algenneen en in de adninistratie van den commissionnair in effecten in het bijzonder.

A III 3 Accountancy December 1935 en Maart 1936
The costing of water undertakings

D r u ry, J. W. - Buchreven wordt de administratieve organisatie vall een waterleidingbedrijf.

A III 3

The Accountant 30 November 1935

The new system of housing accounts

Redactie, - Besnroken worden the Housing Revenue Account, the Housing Repair Account en the Housing Equalisation Account", die volgens de .Housing Act", door woningbouw-vereenigingen moeten worden guhouden.

A III 3

The Accountant 23 November 1935

Government auditing in China

Nom Lee, J. S. - Behandeld wordt de geschiedenis der Chineesche Gouvernementshoekhouding (dateerend van het jaar $2205 \mathrm{v}$ C.) en de huidige inrichting.

A 1113 The Journal of Acconntancy September 1936

De administratie van het groothandelsbedrijf

$\mathrm{H}$ a $\mathrm{mme}$ e, A. - In het bijzonder wordt beschreven, hoe men uit de rekening-courantadministratie onmiddellijk de stand van de rekening van iederen cliënt kan zien en hoe men overschrijding van het maximum-crediet kan voorkomen.

A III 3

Administratieve Arbeid September 1936

Centraal kasbeheer bij het Staatsbedrijf der P.T.T.

$\mathrm{B}(\mathrm{r}$ u y n, J. C. d e) - Het bedrijf staat met de schatkist in rekeung-courant verhouding. Het bedrijf heeft bij de verantwoording van kasmiddelen alleen te maken met de eigen kassen. Voor een rationeele geldvoorziening van de tallooze kantoren zijn deze ingedeeld onder 19 centraalkantoren. Deze onderhouden een relatie met de Nederlandsche Bank (hoofd- en bijkantoor en 17 agentschappen). Alle ontvangsten en uitgaven worden opgenomen in de hoekhouding van het hoofdkantoor. De kas is dagelijks bij. Schr. gaat nader in op details van de organisatie van het kasbeheer.

A III 3

Financied Overheidsbeheer 15 Oct 1936

\section{LEER VAN DE CONTROLE}

Clashes of duty in accountancy and business

B rooks, - Aan de hand van verschillende voorbeelden wordt de begrenzing van de plichten van den accountant besproken. A IV 2

The Accountant 16 November 1935

Influence of internal control upon audit procedure

S te m p f, V. H. - In hoeverre de accountant gebruik zal maken van de in een zaak toegepaste interne controle hangt af van de onstandigheden (karakter van de zaak, de inrichting der administratie, gebruik van mechanische hulpmiddelen). De effectiviteit van de interne controle moet periodiek door een to in details raand onderzoek worden nagegaan. Regels worden gegeven voor een hehoorlijke interne contrôle en voor het onderzoek hiernaar.

A IV 21 The Journal of Accountancy September 1936

De accountantscontrôle on de goederenbeweging

Huiskamp, W. J. - De techniek van de goederen-contrôle wordt besproken.

A IV 3

Accountancy Januari 1936

Test methods in auditing

Redactie, - In ecenige vervolgartikelen wordt het controleeren door steekproeven en de voordeelen die deze mehode kan geven, besproken.

A IV 3

The Accountant 16 November 1935

The accounting control of managed public-houses in the licensed trade

In dit artikel wordt de contrôle door de hrouwerij op de door deze beheerde café's beschreven.

A IV 3

The Accountant 7 December 1935

The control of a departmental store

Finlayson, M. - Besproken wordit de organisatie van den detailhandel en de taak van den accountant in het detailbedrijf.

A IV 3

The Accountant 18 Januari 1936

Influence of internal control upon audit procedure

Ste $\mathrm{mp} f, \quad$ V. H. - In hoeverre de accountant gehruik zal maken van de in een zaak toegepaste interne controle, hangt af van de omstandigheden (karakter van de zaak, de inrichting der administratie. gebruik van mechanische hulpmiddelen). De effectiviteit van de interne contrôle moet periodiek door een tot in details gaan onderzoek worden nagegaan. Regels worden gegeven voor een behoorlijke interne controle en voor het onderzoek hieriaar.

A IV 3

The Journal of Accountancy September 1936 


\section{B. BEDRIJFSHUISHOUDKUNDE}

\section{a. AL GEMEENE BEDRIJFSHUISHOUDKUNDE}

\section{WAARNEMINGSMIDDELEN}

Tusschentijdsche resultatenoverzichten

$\mathrm{Sp}$ its, C. L. - Het tusschentijdsche resultatenoverzicht vervult tweeërlei functies. t.w. die van contrôle-instrument op de gesti van leider en adjunct-leider en die van oriènteeringsmiddel t.a.v. veranderingen in verhoudingen binnen en buiten het bedrij. Schr. werkt deze punten uit.

$\mathrm{B}$ a III 3

Prodiscon Oct. 1936

\section{LEER VAN DEN KUSTPRIJS EN DE PRIJSVORMING}

Eenige beschouwingen omtrent de praktische toepassing van standaardkosten bij het staatsbedrijf der Posterijen, Telegraaf en Telefoon

A d d ens, Drs. Tj. J. en N. Elgersma, -- Besproken worGen: Het nut van standaards; de wijze watop standaards worden bepaald; het „up to date" houden van standaards; het werken met standaards.

B a IV $2 b$

Maandblad voor Accountancy en Bedrijfshuishoudkunde Januari 1936

Aanpassing ook der afschrijvingen

$\mathrm{N}$ ij st, J. J. M. H. - Aan de hand van een artikel van Prof. Dr. J. A. Veraart en een artikel van Ingenieur J. J. Borren, Prof. Lieftinck etc. geeft schrijver cen overzicht en kont tot de conclusie, dat ook de afsclurijvingen moeten worden aangepast en niet de fout van 1919-1928 moet worden gemaakt, dat er te veel dividend werd uitgekeerd en te hooge loonen werden betaald, in plaats van het bedrijf te versterken.

B a IV 6

Accountancy December 1935

\section{LEER VAN DE FINANCIERING}

Some considerations affecting the computation of profits of subsidiary companies

Wolff, $W$. - Besproken wordt aan de hand van voorbeelden, door welke factoren meestal de winst van de holding maatschappij niet gelijk is aan het totaal van de winsten van de dochterondernemingen.

B a $\mathrm{V} 7$

The Accountant 11 Januari 1936

Reconstructie van naamlooze vennootschappen

$\mathrm{N}$ ij st, J. J. M. H. - Besproken worden: wanneer kapitaalreconstructie moet plaats vinder; kapitaalreconstructie in verband met gewijzigde waarde-verhoudingen; conversie van aandeelen. Ook eenige voorbeelden uit de praktijk worden behandeld.

B a V 8 Maandblad voor Accountancy en Bedrijfshuishoudkunde Januari en Februari 1936

\section{LEER VAN DE ORGANISATIE}

\section{Problemen van den detailhandel}

$M$ alle e, K. F. - Behandelt eenige wezenskenmerken van het grootwinkelbedrijf.

$\mathrm{B}$ a VI 9

Administraticve Arbeid September 1936

\section{Les représentants}

$M$ a x out, $M$. - Beschrijft de organisatie van het reizigerspersoneel en de controle op hun rendement o.a. door middel van grafieken betreffende den omzet naar waarde, artikelen en cliënten. B a VI 21 L'Organisation Juli 1936

\section{Uit de praktijk der verkoop-quota}

Vervooren, L. C. - Het doel van de vaststelling van verkoopquota is in wezen tweeledig: dispositief en paedagogisch. Schr. onderscheidt zes verschillende soorten quota en bespreekt dan eenige methoden ter vaststelling der quota's.

B a VI 21

Prodiscon Oct. 1936

\section{LEER VAN DE ARBEIDSVOORWAARDEN}

\section{Iets over het Bedaux-systcem}

$\mathrm{H}$ u i sman, R. I. - Het Bedaux-systeem wil zijn een billijke verlooningsmethode en een voortdurend contrôle-middel. Schr. zet uiteen, wat onder een arbeidseenheid „B" moet worden verstaan, welker vaststelling berust op tijdstudies, waarbij met de arbeidssnel- heid rekening wordt gehouden. Op grond van laboratorimproeven vall Bedaux worden deze waargenomen tijden verhoogd met uiteenloopende opslagen, welke zijn vastgesteld voor een aantal elementaire arbeidsverrichtingen (rustfactor).

B a VII 2

Prodiscon Oct. 1936

Arbeidsstudies als een der vormen van rationalisatie in de klei-industrie

Berenschot, Ir. B. W. - Met behulp van praktische voorbeelden uit de steenindustrie worden arbeidsstudies, welke kunnen leiden tot kostenverlaging, nader toegelicht.

Aan het voorbeeld van het optassen van steenen wordt uiteengezet hoe men arbeidsstudies maakt. Dan volyt een voorbeeld van opstelling bij een persmachine. Uit hetgeen deze gedetailleerde arbeidsanalyses opleverden, blijkt het nut van tijdmetingen voor een juiste tariefstelling. Als volgend voorbeeld dient de kruiwagen.

Resumeerend wordt geconstateerd dat een constant product, een constante productiewijze en een constant personeel factoren zijn, welke een rationalisatie der werkmethoden in de klei-industrie gunstig beïnvloeden.

B a VII 5 ,Klei” 1936 p. 40, 44, 47-48, 5I, 52, 59-60,73-74,80-81

Wat is de waarde van psycho-technisch onderzoek?

Cohen Henriquez, P. - De prognostische waarde van tests is gelimiteerd. Besproken worden intelligentietests, instelligentieschalen, "Einzeltests" en groeptests.

B a VII 5

Administratieve Arbeid September 1936

\section{b. BIJZONDERE BEDRIJVEN \\ I. EXTRACTIEVE BEDIRIJVEN}

Eenige bedrijfseconomische aanteekeningen omtrent mijnbedrijven

B r a a ke, Ir. A. L. t e $r$ en dupliek van A. R itz, - Een poleniek over de economische grenzen van producten-winning in de mijnbouw

B b I 6 Maandblad voor Accountancy en Bedrijfshuishoudkunde December 1935

\section{INDUSTRIE}

Arbeidsstudies als een der vormen van rationalisatie in de klei-industrie

Berenschot, Ir. B. W. - Met behulp van praktische voorbeeiden uit de steenindustrie worden arbeidsstudies, welke kumnen leiden tot kostenverlaging, nader toegelicht.

Aan het voorbeeld van het optassen van steenen wordt niteengezet hoe men arbeidsstudies maakt. Dan volgt een voorbeeld van opstelling bij een persmachine. Uit hetgeen deze gedetailleerden arbeidsanalyses opleverden, blijkt het nut van tijdmetingen voor een juiste tariefstelling. Als volgend voorbeeld dient de kruiwagen.

Resumeerend wordt geconstateerd dat een constant product, een constante productiewijze en een constant personeel factoren zijn, welke een rationalisatie der werkmethodei in de klei-industrie gunstig beïnvloeden.

B b V 10, „Klei” 1936 p. 40, 44, 47-48, 51, 52, 59-60, 73-74, 80-81

In- en verkoopformulees in de textielindustrie

L a n d a u er, dr. E. - Schr. ontwikkelt een aantal formules voor den inkoop van grondstoffen in de textielindustrie. $\mathrm{B}$ b V 13

Prodiscon Oct. 1936

\section{TRANSPORT EN ANDERE DIENSTVERLEENING}

Centraal kasbeheer bij het Staatsbedrijf der P.T.T.

$\mathrm{B}$ ( $\mathrm{r}$ u y n, J. C. d e) - Het bedrijf staat met de schatkist in rekening-courant verhouding. Het bedrijf heeft bij de verantwoording van kasmiddelen alleen te maken met de eigen kassen. Voor een rationeele geldvoorziening van de tallooze kantoren zijn deze ingedeeld onder 19 centraalkantoren. Deze onderlouden een relatie met de Nederlandsche Bank (hoofä- en bijkantoor en 17 agentschappen). Alle ontvangsten en uitgaven worden opgenomen in de boekhouding van het hoofdkantoor. De kas is dagelijks bij. Schr. gaat nader in op details van de organisatie van het kasbeheer.

B b VII $8 \quad$ Financieel Overheidsbeheer 15 Oct. 1936

Eenige beschouwingen umtrent de praktische toepassing van standaardkosten bij net Staatsbedrijf der Posterijen, Telegraaf en Telefoon

Addens, Drs. Tj. J. en N. Elgersma, -- Besproken worden: Het nut van standaards; de wijze waarop standaards worden bepaald; het ,up to date" houden van standaards; het werken met standaards.

$\mathrm{B}$ b VIl 8 Maandblad voor Accountancy en Bedrijfshuishoudkunde Januari 1936 


\section{VERZEKERING}

The general principles and practice of insurance

Jones, T. O. - Behandelt de algemeene principes van het assurantiewezen en in het bijzonder van de bedrijfsschade-verzekering, welke van speciaal belang voor accountants wordt geacht. B b IX 6

The Accountant Student September 1936

\section{BOEKEN-REPERTORIUM}

\section{A. ACCOUNTANCY}

\section{HET ACCOUNTANTSBEROEP}

May, G. O. Twenty-five years of accounting responsibility, 19111936. New York, 1936.

\section{LEER VAN DE INRICHTING}

Bayliss, W. I. Introduction to book-keeping. New York, 1936. Bcisel, Karl. Neuzeitliche Gestaltung des industriellen Rechnungswesens. Leipzig, 1936

Bennett, G. E. Bookkeeping. Principles and practice. New York, 1936.

Rowland, S. W. Accounting. London, 1936

Carmichael, G. Accounting principles and practice, New York, 1936 Cousins, D. Book-keeping and accounts. London, 1936

Harkink, F. Machinerekenen. Rotterdam, 1936.

MacFarland, $G$. A. and $R$. D. Ayars. Accounting fundamentals. New Yotk, 1936.

Margadant, G. M. W. en M. I. Roggeveen. Leerboek voor het boekhouden. Gorinchen, 1936

Stempels, $B$. $G$. Centralisatie van kasbeheer en administratie bi gemeenten. Arnhem, 1936

\section{LEER VAN DE CONTROLE}

May, G. O. Twenty-five years of accounting responsibility, 19111936. New York, 1936

\section{B. BEDRIJFSHUISHOUDKUNDE}

\section{a. ALGEMEENE BEDRIJFSHUISHOUDKUNDE}

II. BEDRIJFSHUISHOUDKUNDE ALS WETENSCHAP

Bernet, Theophil. Die schweizerische Handelsschule. Zürich, 1936.

\section{WAARNEMINGSMIDDELEN}

Winkelmann, Rudolf. Die Gewinn- und Verlust-Rechnung in Konzernen. Berlin, 1936.

\section{LEER VAN DEN KOSTPRIJS EN DE PRIJSVORMING}

Bormann, H. Die Preisauszeichnungspflicht. Wegweiser durch dit antliche Vorschriften für Handwerk und Einzelhandel. Berlin, 1936. Burton, N. L. Introduction to cost accounting. New York, 1936.

Liefmann-Keil, Elisabeth. Organisierte Konkurrenz-Preisbildung. Grosshandels-versteigerung und Warenbörse. Leipzig, 1936.

Schäfer, Martha. Aktivierungsrecht und Aktivierungspficht in der Handelsbilanz und der Einkommen- und Körperschaftssteuerbilanz. Stuttgart, 1936.

\section{LEER VAN DE FINANCIERING}

Bretey, P. R. Opportunities in common stocks. Glen Rock, N. J. 1936.

Dorr, B. Bank and insurance stocks and your income taxes. Boston, 1936.

Eich, Jakob. Die Wertnapierverwaltung der Gemeindekassen. (Verwaltung des Kanitalvermögens). Köln, 1936.

Hellauce, Erwin. Internationale Finanzplätze. 1hr Wesen und ihre Entstehung unter besonderer Berücksiclitigung Ansterdam. Berlin, 1936.

Kampmann, Kurí. Das Problen der Versorgung der deutschen Mittel- und Kleinindustrie mit langfristigem Kredit. Emsdetten, Westf., 1936.
Tillman, C. How to invest $\$ 2000$. Boston, 1936.

\section{V1. LEER VAN DE ORGANISATIE}

Agnew, H. E. and others. Outlines of marketing. New York, 1936. Bennet, $C$. Influencing the buyer's mind. St. Louis, 1936.

Bineau, Rence. Contribution à l'étude de l'organisation des services de direction et de gestions des entreprises. Paris, 1936.

Dygert, W. B. Advertising. Principles and practice. New York, 1936. Ferlet, Roger. La force de la propaganda. Paris, 1936.

Goode, K. M. How to write advertising. New York, 1936.

Gross, M. Dealer display advertising. New York, 1936.

Holland, $G . V$. Selling of newspaper advertising. Los Angeles, 1936 Haggins, I. E. Creative suggestion. Los Angeles, 1936.

Liefmann-Keil, Elisabeth. Organisierte Konkurrenz-Preisbildung. Grosshandelsversteigerung und Warenbörse. Leipzigr, 1936.

schuitema, E. B. W. Grondslagen van de moderne reclame. Den Haag, 1936

Smith, E. J. Forty-five million friends. A short manual on sales organization and advertising. Foreword: F. Goodenough. New York, 1936

Sutherland, G. O. and W. Padget. Organization of commerce. New York, 1936

Terhorst, Hcinrich. Kartelle und Konzerne in der papiererzengenden Industrie. Krefeld, 1936.

\section{LEER VAN DE ARBEIDSVOURWAARDEN}

Levy, Pierre. La selection dn personnel dans les entreprises de transport. La laboratoire du travail du déseau de l'Etat. Paris, 1936.

\section{b. BIJZONDERE BEDRIJVEN}

\section{BOSCHEXPLOITATIE EN HOUTAANKAP}

Rivers, R. R. How to buy timber. London, 1936.

\section{LANDBOUW- EN CULTUURBEDRIJVEN}

Chu, T. H. Tea trade in central China. London, 1936.

\section{INDUSTRIE}

Ahbe, Otto. Die Praxis und Mängel des Konpensationsgeschäftes. Hamburg, 1936.

Bader, Otto. Die Buchverlags-Unternehmung. Eine privatwirtschaftswissenschaftliche Studie. Siuttgart, 1936.

Kampmann, Kurt. Das Problem der Versorgung der deutschen Mittel- und Kleinindustrie mit langfristigem Kredit. Enisdetten, Westf., 1936.

Kirsch, Wilhelm Michael. Das deutsche Verdingungswesen. Stuttgart, 1936.

Mïnchgesang, Günter. Die Bedeutung der deutschen Mühlenindustrie für die nationalsozialistische Wirtschaftspolitik unter besonderer Beriicksichtigung der thürisigischen Mihlenwitrschaft. Erfurt, 1936.

Terhorst, Heinrich. Kartelle und Konzerne in der papiererzeugenden Industrie. Krefeld, 1936.

\section{HANDEL}

Dennett, $H$. Modern rerail stock control. London, 1936

Doubman, J. R. Principles of retail merchandising. New York, 1936. Harvard University, Bureau of business research. Operating results of department and specialty stores in 1935. Boston, 1936.

Harvard University, Bureau of business research. Operating results of department and specialty stores in the Pacific coast states, 1935. Boston, 1936

Hay'es, I. F. Elementary commerce. New York, 1936.

National retail dry goods association. Twenty-five years of retailing, 1911-1936. New York, 1936.

Sutherland, $G$. $O$. and $W$. Padget. Organization of commerce. New York, 1936

\section{FINANCIERINGSINSTELLINGEN}

Chapnan, C. C. Development of American business and banking thought, 1913-1936. New York, 1936.

Hugi, Bruno. Der amerikanische Investment Trust. Bern, 1936. 